\title{
Visual Narratives: A History of Art at CERN
}

Camilla Mørk Røstvik (art and science historian), University of St Andrews, University of Manchester, U.K. Email: <camilla.rostvik@manchester.ac.uk>.

(c) ISAST

Manuscript received 17 July 2015

ABSTRACT: This article examines the history of art inspired by the European Organization for Nuclear Research (CERN) in the 20th and 21st centuries. The article argues that artists can tell us radically different narratives about this space than mainstream media, scientists and CERN's own PR structure.

Why have so many artists been inspired by the European Organization for Nuclear Research (CERN)? In this article, I examine the history of art inspired by CERN in the 20th and 21st centuries. Artists can tell us radically different narratives about what is often called the most important scientific experiment in the world than scientists and mainstream media. Through observations made onsite and art historical analysis, this article focuses on the role of the artist at CERN. Art is considered in its broadest form to include all visual and conceptual creative work, including graffiti and literature, TV and films. This is done to break down the hierarchies found within the art world and present CERN as a visual culture from many angles. The article does not discuss the current art program Arts@CERN, but presents some background upon which to understand this new, digitally focused cluster of projects [1]. Toward the end of the article a discussion of art that deals in more critical themes connected to CERN is presented to compare with the majority of works that celebrate the organization. These examples provide insight into the eclectic "many worlds" of CERN.

\section{Meyrin and Its Ruins}

As European countries came together to plan and place CERN in the mid-1950s, they discussed various sites of interest and settled on a site outside of Geneva in Switzerland [2]. Meyrin was a tiny agricultural village until CERN moved in, bringing with it jobs, buildings and shops. Today many of the laboratory's workers live near or in the village, making it one of the highest physicist populated places in the world. However, before the scattered buildings and farms on the outskirts of Switzerland could become host to some of the world's leading scientists and engineers, the ancient ground would have to be carefully documented. A team of archaeologists from the Rhone-Alps Regional Archaeology Service, together with the LHC authorities, compiled surveys to assess the sectors for archaeological potential. 
From this excavation two Roman columns were allocated to CERN. The organization describes this as "2000 year old technology transfer" placed in the central library to be "enjoyed by all" [3]. This is one of the first instances of the organization's interest in composing its own visual and cultural narrative. As this paper explores, visual culture is an important part of CERN's image.

Above the Roman ruins the discussion of CERN's architecture was soon underway. By 1953 the architect Dr Steiger was chosen and the same year he drew up the first preliminary site map of CERN [4]. He was greeted with urgency and confusion. The budget set aside for aesthetics was minimal. A process of constant pressures on and from the architect followed, including discussions about funding and timescale [5]. The lack of someone who took an active interest in the architect's issues became particularly problematic, as Steiger and his firm was left to make major decisions of scale and aesthetics alone. He was the first in a long line of outsiders who would find working with the international, ambitious group of scientific men both exciting and challenging. As an architect Steiger could never quite cross the Two Cultures climate of the 1950s, which often pitted art against science as famously discussed by C.P. Snow in the 1959 Reith Lectures [6]. Often dismissed as a simplification, Snow's observation about a fundamental divide between the arts and sciences is at times visible at CERN.

Compared to the focus on the arts (and craft) at other high-energy physics laboratories such as Robert Wilson's Fermilab, aesthetic was not a guiding mission for the young organization. Whereas Wilson and other American counterparts could spend money on highly visual grand frontier-narratives, and time on visiting artists, their post-war European counterpart had to ensure that the focus was all science, all the time. The infamous artist James Lee Byars 1972 visit is a case in point. Self-styled as "the world's most famous unknown artist," Byars life was an eccentric performance and his visit to CERN was part of it. Byars writes about his time at CERN in his characteristic complicated style based on abbreviations of language. He visited the laboratory for two weeks and was subsequently put on the cover of the internal magazine CERN Courier in September 1972. Byars became friends with several scientists, in particular physicist John Bell, and immersed himself in the intellectual environment onsite. Dressed in gold sunglasses, gold tennis shoes, and a Panama hat he embodied the idea of the outsider. Although his time at CERN gave him inspiration and was "perfect," Byars also recalls that it could have been made "more perfect" by giving him an invitation to undertake art projects onsite. The artist was largely left to himself onsite, 
welcome to wander around and snap self-portraits. As a consequence, only scattered notes and some photographs tell the tale. Byars called for "opportunities" for artists and "serious consideration" with some "additional investment on their part as to what type of relationship it could be." He wrote he was perhaps "asking a very great amount because, already, they have the whole work on their back, without having to consider these luxurious elements of metaphysics" [7]. Some of his suggestions can be seen in the contemporary art program Arts@CERN and the artist in residency scheme Collide@CERN today, in particular the focus on creating conversations between artists and scientists.

\section{Sculptures and Personalities}

CERN's culture, from the fetishization of large machines to the focus on computer graphics, is visual. The sculptures on site also tell stories of power and history. The first artwork visitors see is the late Swiss sculptor André Bucher's large abstract stone sculpture Matiere from 1985 (Fig. 1) [8]. Placed in front of the visitor's entrance, it is a square metal form that has had its intestines carved out in the form of a spiral. Matiere was donated by the Societe de Banque Suisse, which has always had close links with CERN, providing ATMs and services onsite in later years. In this crucial spot, the visitor's first glimpse of CERN, the sculpture provides an aesthetic welcome to the laboratory. The artist loved science and visited the organization several times. Bucher's object is matter and antimatter, space and absence. Art at CERN, although not necessarily intended for great symbolic gesture, sometimes has the power to provide a meditative space beyond science. A bit worn down and endowed with the scribble of seagulls, Matiere remains a rare piece of nontechnological and abstract art onsite.

CERN's more traditional sculptures exhibit the likeness of Wolfgang Pauli, Cornelius Jan Bakker, Niels Bohr and Marie Curie among others (Fig. 2). These are memories of great individuals, placed to remember their work and life in a place relevant to both. Pauli and Bakker were unveiled in 1960. The latter was commissioned after he was killed in an air crash during his time as Director General, an event that is still traumatic for the laboratory. As a focal point for mourning, the object can provide a quiet space for shared memories. Bohr's bust was given its place in 1963 whereas the quite weary Marie Curie bust communicates a story of nationhood and taste. She is placed slightly off-center in the foyer of the CERN visitor building. Curie is the first work of art portraying a person that the visitor will see, although slightly dishevelled and placed in a corner. As one of the most famous 
scientists in the world, she communicates international links and success, although she did not have any real-life connection to CERN. She is also, to my best knowledge, the sole example of a female scientist represented in any of the CERN art onsite. On my last visit our enthusiastic guide explained this piece by the fact that "...countries like to give CERN presents because they get something back, like jobs." The bust was donated by the Polish Deputy Minister of Energy and Nuclear Power, J. Felicki, and presented to the Director General on behalf of physicists of Poland in 1974. Dead twenty years before CERN was founded, Curie ties the laboratory to a history of science. The traditional busts dotted around CERN are reminders of the great personalities of science, as are the CERN streets named after scientists. They also tell stories of decay. Beloved as these names are, their power has ebbed and flowed with the new discoveries in high-energy physics. These weary sculptures speak of a wish to conserve the memories of a field where everything can change at the discovery of a new particle. When your workspace seeks to describe, understand and see the building blocks of the universe, the solid matter of a historical sculpture can bring insight into a lost past.

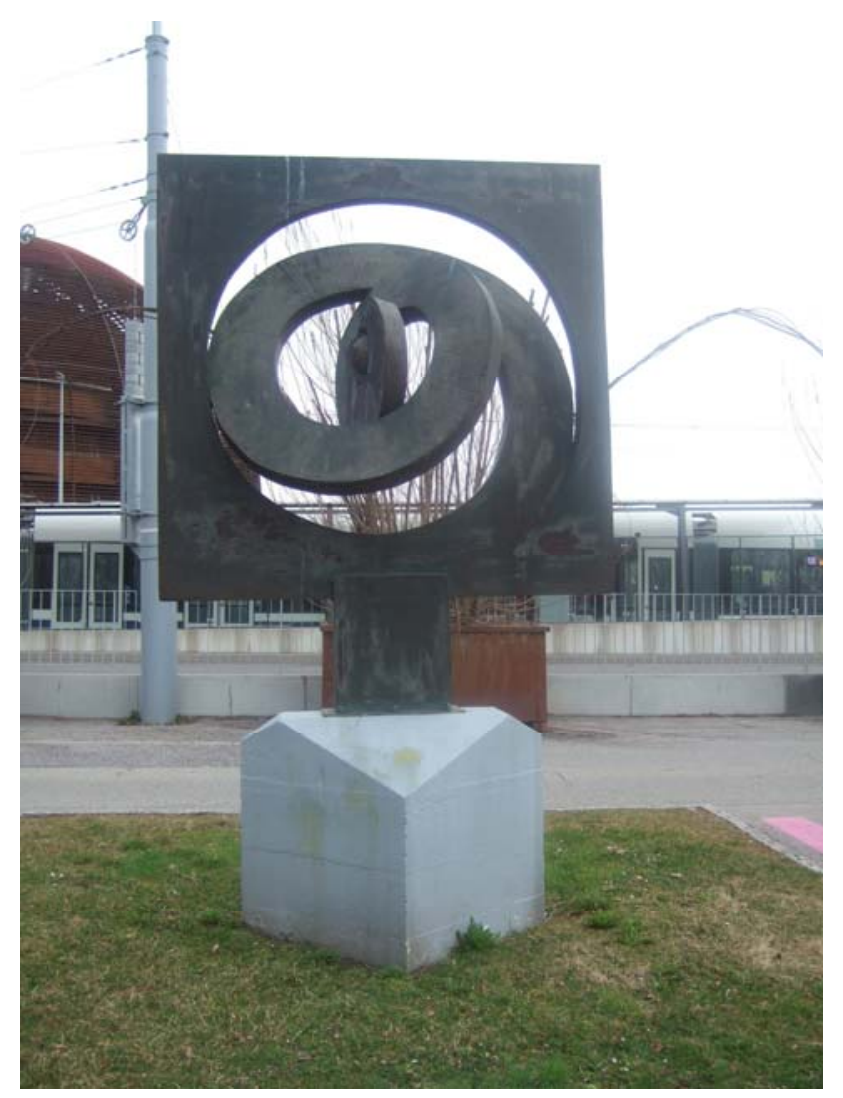

Fig. 1. André Bucher, Matiere, 1985. (CAndré Bucher. Photo: Camilla Mørk Røstvik.) 


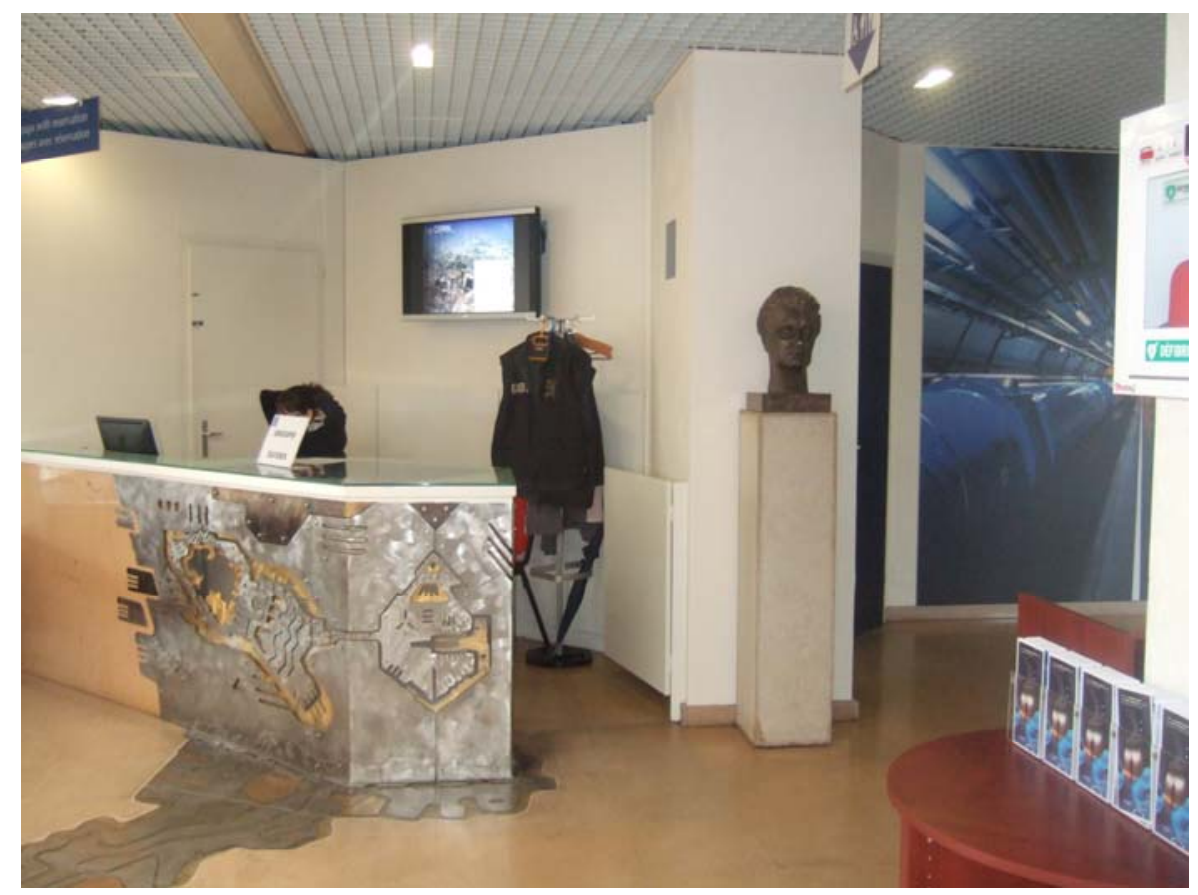

Fig. 2. Unknown artist, Bust of Marie Curie, 1974. (Photo: Camilla Mørk Røstvik)

The next sculpture visitors' encounter at CERN is the late Serge Moro's eclectic floor piece Cosmic Song from 1987, which covers most of the floor of the foyer in the visitor's center (Fig. 3) [9]. As a slab of metal, light and abstract shapes, the artwork is impossible to ignore. The work is also a cosmic ray detector embedded into the floor. It was made in collaboration with a CERN workshop in 1987, and lights up in a range of bright colours with the "constant rain of cosmic particles from outer space." Visitors and staff at CERN seem ever confused and entertained by the object. It remains a surprising center of the room where laypeople enter the laboratory, an example of illustrating the complex and invisible science being done in other spaces of the laboratory. Making meaning at CERN is tied up to understanding minute worlds far beyond the human eye's capacity for observation. Moro's piece is in a sense the opposite: larger-than-life, colourful and bold. Artists that work with the concepts of high-energy physics often play with these contrasts. This can tell us something about the values ascribed to both spheres of activity. Meaning at CERN is tied up in a scientific worldview. Visiting artists are allowed space to explore concepts without the burden of having to discover something new. The freedom of the artist might be interpreted as without structure, but within the playful creativity of art there is also outlets for discovery. 


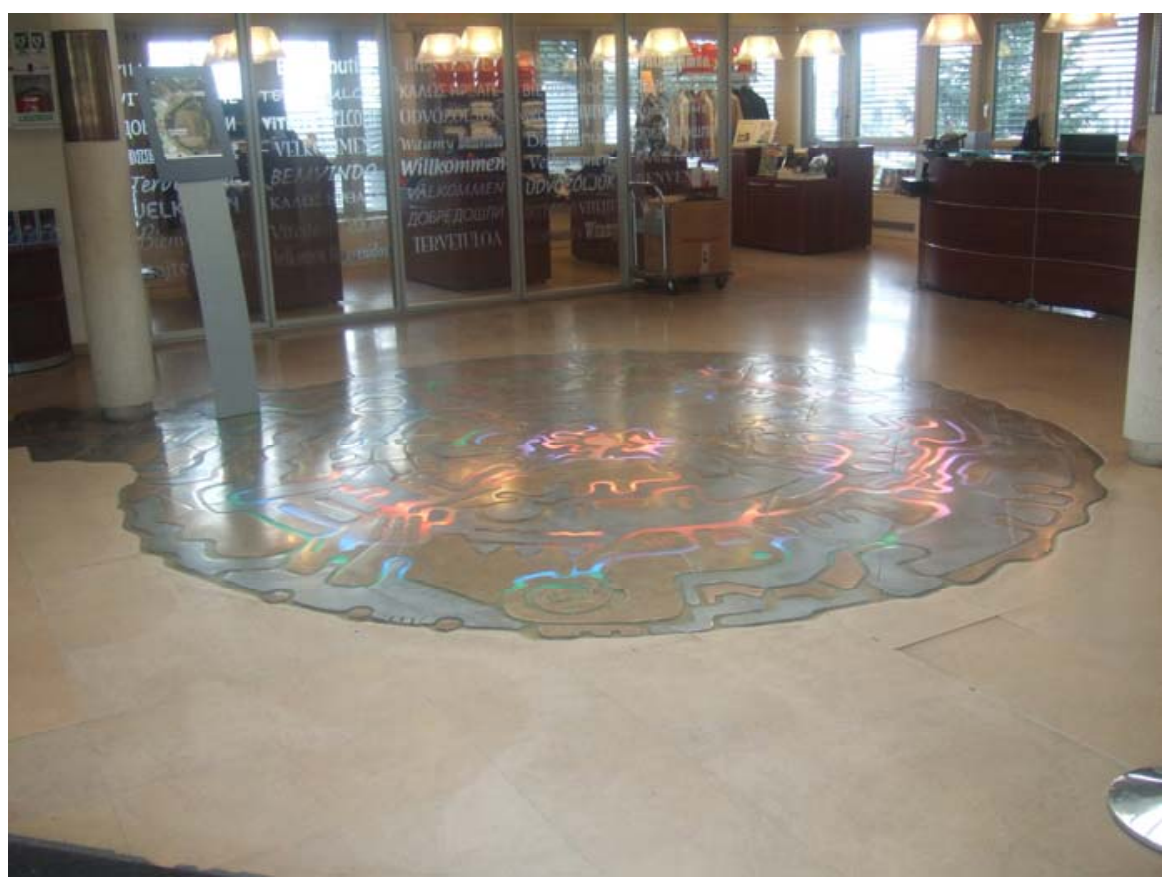

Fig. 3. Serge Moro, Cosmic Song, 1987. (C) Serge Moro. Photo: Camilla Mørk Røstvik.)

Heading towards the main cafeteria visitors will see Anthony Gormley's sculpture Feeling Material XXXIV from 2008. Described as "hanging scribbles" by journalist Suzanne Moore, it is an example of art inspired by an artist's visit to the laboratory. It was allegedly rediscovered in a cardboard box in the archives. The unveiling of the new placement was done by the British Ambassador to the Swiss Confederation, Sarah Gillett (now Ambassador to Norway). The rehanging was part of a larger redecoration of the main building including a renovated gallery of portraits of CERN's former Director Generals. The "warm and friendly" atmosphere has created a space for CERN staff and visitors to meet, talk and eat [10]. It is a social space filled with cultural objects, where the rediscovery of Feeling Material XXXIV in part catalysed the reimagining of the area. The focus on aesthetics at CERN alludes to a wish for spending more time with cultural objects, perhaps as opposed or in combination with the scientific worldview often seen to dominate high-energy physicists' vision. Perceived to be ignored by scientists and deployed by everyone else, cultural objects such as artworks come with narratives and histories created distinctly by a shared culture. The exploration of Feeling Material XXXIV's subatomic structures would not necessarily tell us anything more than the work itself communicates. 


\section{Machine Art}

CERN's powerful machines are celebrated for their beauty, as well as their functionality. Particle physicist Carlo Rubbia stated: "Detectors are really the way to express yourself. To say somehow what you have in your guts. In the case of painters, it is painting. In the case of sculptors, it's sculpture. In the case of experimental physics, it's detectors. The detector is the image of the guy who designed it" [11]. In addition to the famous LHC collider, the built landscape holds several of the large, famous and expensive objects of past discoveries at CERN. In the courtyard behind the visitor's center and main office buildings, trees and pathways are populated by elevated space ships that gleam in the sunlight (Fig. 4). These are bubble chambers, including Gargamelle, a particle detector of major importance during the initial years of high-energy physics in Europe. The CERN outreach website describing the historical importance of bubble chambers is also quick to point out its visual impact, speaking both about the machine and its aesthetically arresting output: "Even today, bubble chamber photographs provide the aesthetically most appealing visualization of sub nuclear collisions" [12]. Working as both aesthetic objects and information, Gargamelle and the other machines also serve the function of filling in the gaps where visitors cannot visit, in particularly underground. This suggests that the machines can be more successful at conveying meaning than both sculptures and people. Another piece takes this even further.

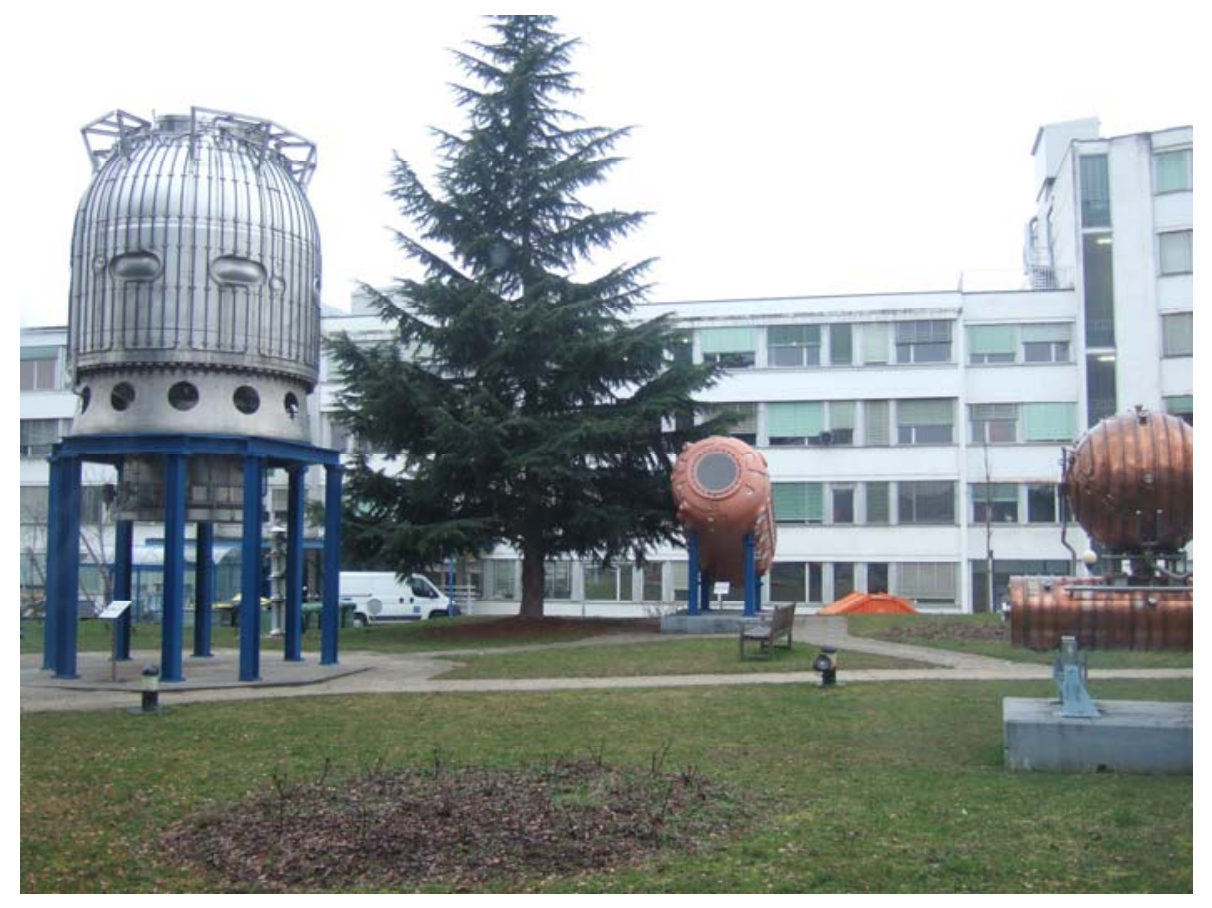

Fig. 4. Bubble chambers in one of the CERN courtyards in 2014. (Photo: Camilla Mørk Røstvik) 
In Joseph Kristofoletti's large mural of the ATLAS detector made around 2010 the detector below ground is brought to the surface (Fig. 5). Painted onto one of the large walls of the ATLAS experiment it is situated in close proximity to the object it is depicting. The bright colours highlight every facet of the detector, depicting the large machine as a bright and uplifting work of art. The mural has become a part of the route of the ATLAS visitor tours, delighting visitors and functioning as an illustration for the real machine when the belowground areas are closed of. Visitors snap photographs of the work on their phones, and mainstream media often turn to this work to illustrate CERN as a whole. In articles such as the 2013 Guardian piece about CERN's work post-Higgs, the artwork serves as the illustration, although the artist's name is not included [13]. As an oddity, the mural was welcomed into the creative culture of ATLAS at the turn of the century. Its uplifting and colourful rendering of a subject some might find dull has made it much loved by CERN visitors. As a part of the eclectic onsite art collection, it is one of the key works of art at CERN. The reproduction of CERN's machines in art and on cell-phones alludes to a wish for fixing a visual moment in a field of invisible currency. Flooded with data, particles and interpretation, artworks are sometimes the only way of actually seeing CERN.

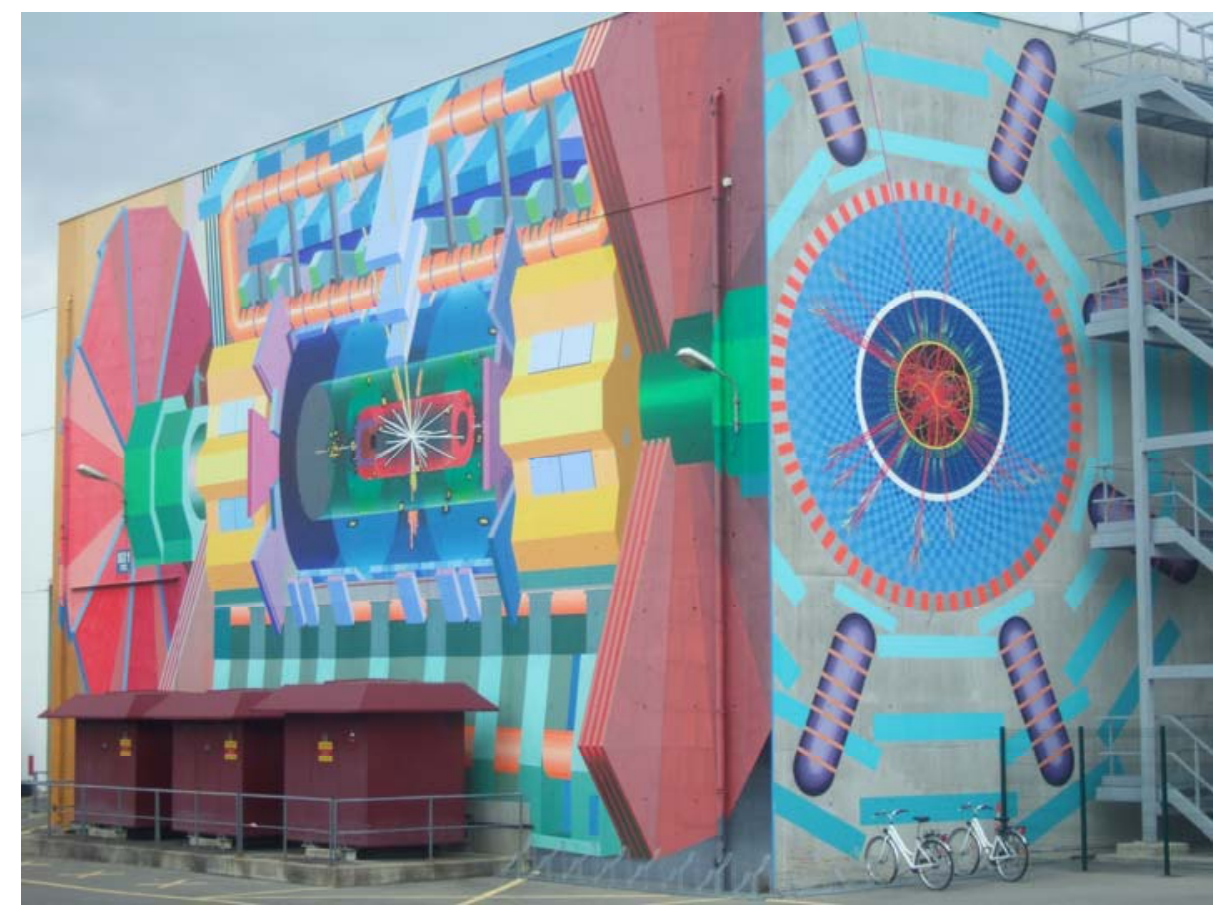

Fig. 5. Joseph Kristofoletti, ATLAS wall mural, ca. 2010. (CJoseph Kristofoletti. Photo: Camilla Mørk Røstvik.) 
A less-known and visible work of art that also engages in direct action with the built environment and machines at CERN is Gianni Motti's performance piece Walking for Art's Sake and the accompanying series of photographs Looking for the Anti-Motti from 2005 [14] Motti visited in 2005 and sought to colonialize CERN with art through his performance where he "compared himself to a proton." Descending into the circular tunnel that would soon house the LHC, Motti walked the twenty-seven kilometres "at the average, unaccelerated pace of five kilometres per hour." Motti's controversial career, which took off when he staged his own death and funeral in 1989, is never shy of flirting with authority [15]. Instead of simply illustrating the seductive machines onsite, Motti occupied CERN and, in this fleeting settlement, succeeds in bringing the outsider inside these usually closed spaces.

This small selection of art that engages with CERN's machines are examples of the public interest in the organization. As a tourist attraction, CERN's old machines are exhibited to inform, delight and historicise this hyper-modern setting. They also serve the purpose of soothing disappointed visitors who will not be able to go underground at CERN to see the modern machinery when it is closed. In common for all the artworks that engage in a conversation with CERN's machines is the wish to express the mysterious, scientific and complex worlds that they inhabit. Visitors want to understand the machine, be able to imagine it and know its scale. Through experiencing art, they can.

\section{Critical Art}

Not all artists seek to celebrate CERN. The following are some case studies chosen to give a broad insight into the topics of controversy that artists working in many mediums have engaged with. It should be noted that critique of CERN is found mostly in science fiction and the documentary film genre rather than in 'high art.' They give insight into the meaning of CERN and, in a few instances, its particular problems.

Crime writers of books and TV Dan Brown, Russel Davis and Robert Harris have been inspired by CERN, and written about its security issues in their respective books Angels and Demons (2000) and The Fear Index (2011), and television series Torchwood (2008). Angels and Demons, later turned into a Hollywood blockbuster starring Tom Hanks, follows sexy Harvard symbologist Robert Langdon in his efforts to stop the secret society of the Illuminati from destroying Vatican City with antimatter stolen from CERN. On the way Langdon goes to Meyrin and meets equally sexy CERN scientist Vittoria, before they set out to stop the end of the world. In The Fear Index, also scheduled for the big screen, former CERN scientist and 
multibillionaire Dr Alex Hoffman has developed a new form of artificial intelligence that tracks human emotions, making it possible for his machine to predict movements in the stock marked. Hoffman's funds are based in Geneva, where he retired from working at CERN after making his first million. In the Torchwood episode set at CERN, people are disappearing from the site due to side effects from the LHC activation. These three interpretations of CERN all focus on the dangers of black holes, terrorism and blackmail within a semifictional field of physics. This has openly been embraced as a great PR opportunity for CERN. As head of communications James Gillies wrote in relation to the BBC4 program:

As one of the leading centers of scientific research, what does CERN do when it finds itself turning up in works of fiction like Torchwood or Angels and Demons? It has three choices: it can rail at the inaccuracy of the science in the fiction; it can bury its institutional head in a bucket of sand. Or, it can seize the opportunity to get physics on the public agenda - and this is what CERN has chosen to do [16].

CERN had its own take on these creative interpretations. As the film Angels and Demons was released, CERN set up a website about the book and the film, and with a focus on incorrect science that inspired it [17]. Functioning as a factual check and balance, the website provides all the scientific information that the book misrepresents in a playful tone. CERN was also involved in the production of Torchwood where representatives of the organization read the script to check for scientific accuracy. The episode was part of the celebration of the switch on of the LHC in 2008 and was seeped in CERN from scripts to interviews, documentaries to music [18]. Robert Harris visited CERN to gain inspiration and knowledge about the site crucial to his plot in The Fear Index, and is featured in the contemporary Arts@CERN gallery of projects online [19]. The fact that Angels and Demons, The Fear Index and Torchwood are fiction does not make CERN shy away from making sure the interpretations do not give the public the wrong associations, even though the organization itself has been active in its script-writing. In CERN's early years the young organization spent time constantly reassuring the public that it was not a nuclear bomb making machine or a military plot. Today creative licence is as uncomfortable for CERN to deal with as the military question used to be, because artists such as Brown, Harris and Davies either invoke exactly those old difficult security concerns, or dream up new alternatives. The organization's reaction and involvement in Angels and Demons, Torchwood and The Fear Index is symptomatic of their attitude to the importance of correct information [20]. 


\section{Three Films}

Recently, the medium of film- and documentary-making has been increasingly used to engage critically with CERN. The directors and producers behind the short science fiction film Rift provide an alternative view of CERN's work [21]. Produced in 2009 the short film circles on the controversial debate a year prior about the possible negative consequences of switching on the LHC. The narrative follows one CERN staff member through one day, spanning breakfast with his family, the announcement of the switch-on of the LHC and its fictitious dystopian consequences. Echoing fears that dissenters such as Otto Rössler and others have expressed through legal disputes and on $<w w w . l i f e b o a t . c o m>$, it is a "surreal interpretation of Pandora's box" [22]. The failed experiment ends in a formation of a black hole that alters the space and time of the scientist's own life. As the world ends, the scientist sees a rift in the sky: a black hole. He is forced to relive his day and the disaster again and again as a loop of discovery and destruction. The original aspect of Rift is that it performs its message in an accessible form, available on YouTube for free, adopting the tropes of Hollywood to communicate to a vast audience. The film thrives on tropes, but nevertheless remains an important alternative storytelling narrative compared with most art inspired by CERN.

In the aforementioned documentary, CERN People-Unrequited Love, CERN staff are portrayed wrestling with the uncertainty of their field and life after the discovery of the Higgs boson. Following young scientists in the year of the discovery, the documentary lets them voice their worries about competition. "I'm just so tired of looking for the Higgs," exclaims one young, exhausted man. Another, in one of the CERN subgroups that did not see Higgslike results in 2012, felt "hated by everybody" because of it. These young men speak about the failures of the CERN community to support everyone. Beyond the champagne and discoveries, the film is a reminder that the laboratory is made up of people, not particles. Although not engaged in an outright critique of CERN, the documentary sheds some light on the importance of failure and seeks to reveal life in high-energy physics to outsiders [23]. Funded by the Science and Technologies Facilities Council of the United Kingdom and the Irish Film Board, the film is in English with no subtitles and directed by London-based director Liz Mermin, a testament to the interest in the culture and life of scientists in the United Kingdom today. 
Finally, Bram Conjaerts' documentary The Circle (2009) provides an important insight into what CERN's neighbours think of its work. Conjaerts wanted to focus on the human side of the field, and when he visited CERN he did not automatically turn towards the physics. Tracing the 27 kilometers LHC, Conjaerts interviewed locals who live on its circular route aboveground. A range of people, from a priest to a farmer, young couples to retired CERN staff, share their thoughts. The documentary leaves out the scientists, who are only present through sparse audio. This was a choice Conjaerts was eager to employ in order to focus on the neighbours. The locals thus provide most of the commentary, ranging from proud enthusiasm to sadness, even fear. Perhaps no one knows CERN better than these people, the neighbours that deal with visitors, press, sound, radiation and bureaucracy. Conjaerts was never afraid of controversy, interviewing prominent CERN-dissenter Otto Rössler ("The scientists laughed") and asking difficult questions. Conjaerts found that he had to "earn the trust of the PR office" in order for him to get access to the scientists [24].

These three films, Rift, CERN People and The Circle, have not reached a large, mainstream audience. Their semicontroversial interpretations of CERN has perhaps understandably not been actively endorsed by the organization and thus the artists have not been able to share their work via the organization's large public platform online, onsite and by reputation.

\section{Les Horribles Cernettes}

One of the most surprising critical artistic interpretations of CERN comes from a group of outsiders within the organization itself. The female-led parody pop group Les Horribles Cernettes was founded in 1990 and made up of "Cernoises" (the term for CERN women originated at the CERN Women's Club). Their perspective on their boundary position as women at CERN is explored in the lyrics [25]. With the aggressive and ironic name Les Horribles Cernettes, the band's ethics are on display and became CERN's very own feminist house organ. Titles such as "Daddy's Lab," "My Sweetheart Is a Nobel Prize" and "Mr. Higgs" play with the traditional pop themes of love and heartache, with an original twist on science and the life of scientists. Les Horribles Cernettes maintain their position as one of the very few female-led art project that has come out of CERN. CERN is famously historically dominated by men (although a more active Diversity officer and the announcement of the 
organization's first female Director General Fabiola Gianotti will hopefully change this in the near future.) Les Horribles Cernettes symbolizes an exemption, as the lines of Collider show:

You never spend your nights with me

You don't go out with other girls either

You only love your collider [26]

Les Horribles Cernettes utilizes all the strategies of the pop culture-oriented "third wave" feminist movement, emerging as one of the most critically engaged artworks to come out of CERN. Compared to other artists that engage with CERN, the group knew the organization intimately, and their insights are based on actual observation of the human entities that interact on site. The group's texts are reminders of a workspace made up of people, not particles. Les Horribles Cernettes are much loved within the high-energy physics community, but have been largely ignored in writing about CERN's culture and in the new art programs. As one of the only cultural projects at CERN to use feminism, the world they present is yet another manifestation of the complexity of this space.

\section{Conclusion}

As explored in this article, the artists that have engaged with CERN through history, from the architect to Les Horrible Cernettes, create a history that reveals more than science. Whether contrubuting to CERN's mission or struggling with it, their work ensures that more than the CERN PR version of history will survive. Nevertheless, even the most controversial artworks that explore CERN do not actually hurt the organization's reputation. Rather they create a rich tapestry of opinions that invite a vast array of characters to engage with the organization and its work. Controversy in art has always been important, something that ensures political and social conscience in hierarchies. It is the art that engages in CERN's more controversial aspects that is most rewarding to watch, listen to and explore. It tells us more than CERN itself can, it collapses the superficial structures of the PR narrative and explores the deep and varied "many worlds" of CERN.

\section{Acknowledgments}

Many thanks to CERN, the artists and the artists' families for agreeing to the use of the photographs taken at the site. 


\section{References and Notes}

1. Arts@CERN website, <http://arts.web.cern.ch>, accessed 22.10.2015.

2. Armin Hermann, Lanfranco Belloni, John G. Krige, Ulrike Mersits, Dominique Pestre, History of CERN Volume 1 (Amsterdam: Elsevier Science, 1987), 238.

3. Laurent Guiraud, photographs of woman and Roman columns in CERN Library, CERN archives document server, CERN-GE-0103011-01 and CERN-GE-0103011-02 (08.03.2001).

4. Steiger, first preliminary map of CERN site and buildings, CERN-L-REP 4, Jan 1953 (CERN archives).

5. Hermann et al., History of CERN, Volume II, 17.

6. C.P. Snow, The Two Cultures, first published 1959 (Canto Classics, 1998).

7. Magalia Arriola and Peter Eleey, eds., James Lee Byars, 1/2 an Autobiography (Vol. 1 Sourcebook) (Köhn: Koenig Books, 2014). Many thanks to Alexander Brown for providing a scan of the book.

8. Thanks to Bücher's family for reading this and for the rights to use the photograph.

9. Thanks to Moro's family for reading this and for the right to use the photograph.

10. "Renovating the CERN main building", CERN Bulletin No. 25-26/2010 (21.06.2010).

11. Carlo Rubbia quoted in Galison, Image and Logic, A Material Culture of Microphysics (Chicago: University of Chicago, 1997), xviii.

12. Rudolf K. Bock, “Bubble Chamber,” CERN website (9.04.1998).

13. Moore, "After the Higgs hype..."

14. Gianni Motti, Walking for Arts Sake, CERN, 2005 (some excerpts from the six hour performance from YouTube, uploaded 24.08.2008), <https://www.youtube .com/watch? $\mathrm{v}=\mathrm{gUkYfcPAodM}>$, accessed 7.01.2015.

15. Tirdad Zolghadr, "Gianni Motti.” Frieze, Issue 82 (April 2004).

16. “CERN in Science-Fiction”, BBC website (undated), <http://www.bbc.co.uk/ radio4/bigbang/sciencefiction.shtml?select=page2\#article $>$, accessed 5.12.2014.

17. CERN, "Angels and Demons, the science behind the story," CERN Accelerating science website (2011), <http://angelsanddemons.web.cern.ch>, accessed 4.05.2016.

18. Mark Wright, “Torchwood-Lost Souls,” The Stage TV (10.11.2008).

19. Arts@CERN gallery of past projects, page 2, <http://arts.web.cern.ch/ gallery?page=1>, accessed 4.5.2016.

20. See for example, "Antimatter and other mysteries in the ATLAS experiment," ATLAS PDF (undated).

21. Andy Huang, Rift YouTube (uploaded 29.09.2009), <https://www.youtube.com/ watch? $=$ msnZShgdBrY $>$, accessed 5.12.2014.

22. Collider exhibition pamphlet, The Science Museum London, 14. <www.lifeboat .com> is a conspiracy theory website where dissenters from various sciences meet to discuss and plan action. Scientist Otto Rössler is known for criticising CERN's work and ethos and is dismissed by the organization and wider scientific community as a conspiracy theorist. 
23. CERN People, YouTube (last update 16.09.2014), <https://www.youtube.com/ playlist?list=PLQTF-1oWnPbbXTkPYQG8Ak6OPntnkhqGK>, accessed 3.09.2014.

24. Røstvik interview with Conjaerts, 18.07.2014.

25. Les Horribles Cernettes website, $<$ http://musiclub.web.cern.ch/MusiClub/ bands/cernettes/>, accessed 5.12.2014.

26. Les Horribles Cernettes, Collider, 1994.

\section{Selected Bibliography}

CERN archives: http://library.web.cern.ch/archives/CERN_archive

Galison, Peter. Image and Logic. A Material Culture of Microphysics. Chicago: University of Chicago, 1997.

Hermann, Armin; Lanfranco Belloni; John G. Krige, Ulrike Mersits, Dominique Pestre. History of CERN, Volumes I-III. Amsterdam: Elsevier Science, 1996.

Kemp, Martin. Seen Unseen: Art, science, and Intuition from Leonardo to the Hubble telescope. Oxford: Oxford University Press, 2006.

Knorr-Cetina, Karin. Epistemic Cultures. Harvard: Harvard University Press, 1999.

Randall, Lisa. Higgs discovery. The Power of Empty Space. London: The Bodley Head, 2012. 